\title{
Optimization of Nitrate Reduction by Electrocoagulation Using Response Surface Methodology
}

\author{
Hooshyar Hossini ${ }^{1}$; Abbas Rezaee ${ }^{1, *}$ \\ ${ }^{1}$ Department of Environmental Health, Tarbiat Modares University, Tehran, IR Iran \\ ${ }^{*}$ Corresponding author: Abbas Rezaee, Department of Environmental Health, Tarbiat Modares University, Tehran, IR Iran. Tel: +98-2182883575, Fax: +98-2182883575, E-mail: rezaee@ \\ modares.ac.ir
}

Received: January 23, 2014; Revised: April 24, 2014; Accepted: April 25, 2014

\begin{abstract}
Background: The presence of nitrate and its intermediates are considered undesirable compounds in the environment. Various methods have been proposed to remove nitrate from wastewater and water streams.

Objectives: In this study, we investigated removal of nitrate from an aqueous solution by the process of electrocoagulation, using aluminum/graphite as the anode/cathode electrodes.

Materials and Methods: We applied response surface methodology (RSM) as the statistical method for modeling, and optimizing the applied variables. All experiments were performed according to the standard methods for the examination of water and wastewater. To prepare the optimum condition, we considered the following amount of compounds and conditions: $\mathrm{NaCl}, 1 \mathrm{~g} / \mathrm{L}$; nitrate concentration range, 50-200 mg/L; applied electric current range, 0.05-0.2 A; anode, aluminum; cathode, graphite; and detention time: 120 minutes.

Results: The results showed that by applying electric current of $0.14 \mathrm{~A}$ for 120 minutes, the nitrate content would reduce down to $97 \%$. The obtained $\mathrm{R}^{2}$ for the nitrate removal model was higher than 0.99 . With regard to supporting electrolytes, more nitrate reduction is obtained with $\mathrm{NaCl}$. The oxidation reduction potential (ORP) was changed from 220 to-375 $\mathrm{mV}$ and this range is suitable for denitrification and nitrate reduction.

Conclusions: The results of this study show that it is possible to remove nitrate, and its intermediates from waste water. Regarding the desirability of the process, the field scale study is proposed.
\end{abstract}

Keywords: Electrocoagulation; Nitrate Removal; Waste Water; Water

\section{Background}

Nitrate and its intermediates are considered undesirable compounds in water and wastewater. The nitrate contamination is an environmental problem in many sources of water $(1,2)$. The ecological effects and toxicology of the nitrate compounds have been reported in different studies $(3,4)$. Major sources of nitrate can be used for agricultural fertilizers and wastewater discharges $(5,6)$. The most adverse effects of nitrate can be mentioned as: eutrophication, methemoglobin, toxicity to aquatics and potential health hazards to infants and pregnant women $(2,5)$.

Hence, nitrate removal from water and wastewater is considered as an environmental health concern. According to the World Health Organization (WHO) recommendations, the maximum allowable concentration of nitrate in drinking water is $50 \mathrm{mg} / \mathrm{L}$ (7). Various methods for nitrate elimination were reported such as ion exchange, biological treatment, reverse osmosis, chemical reduction, and electrochemical processes (7-9). These conventional technologies have some disadvantages such as generating a large amount of intermediates, which require further treatment, continuous monitoring, and slow kinetics rate (8-11).

Electrochemical method is preferred, because of the advantages such as 1) environmentally-friendly technology,
2) high effectiveness process, 3) no addition of chemical requirements, 4) small occupied area, 5) generating small volume of sludge, 6) simplicity of the operation and maintenance, and 7) relatively low investment cost $(12,13)$. Electrocoagulation is an efficient, credible and low-cost method for treating a large variety of wastewater bodies such as industrial wastewater, municipal wastewater, chemical oxygen demand (COD ) removal, dyes, oil-water emulsions, and heavy metal-containing solutions $(14,15)$. Nitrate removal was reported using different electrodes $(16,17)$.

\section{Objectives}

During this study, we investigated the following subjects: 1) Evaluation of electrochemical potential for elimination of nitrate and its intermediates using aluminumgraphite electrodes,

2) Evaluation of combining affinity of electrocoagulation and air stripping,

3) Statistical analysis of experimental data using response surface methodology.

To the best of our knowledge and based on the literature review, optimization of electrocoagulation-reduc-

Copyright (c) 2014, Health Promotion Research Center. This is an open-access article distributed under the terms of the Creative Commons Attribution License, which permits unrestricted use, distribution, and reproduction in any medium, provided the original work is properly cited. 
tion treatment of nitrate from wastewater using the response surface method has not been reported yet.

\section{Materials and Methods}

\subsection{Materials}

The materials, including $\mathrm{KNO}_{3}, \mathrm{NaCl}, \mathrm{KCl}, \mathrm{Na}_{2} \mathrm{CO}_{3}, \mathrm{HCl}$, $\mathrm{H}_{2} \mathrm{SO}_{4}, \mathrm{HgI}_{2}, \mathrm{KI}, \mathrm{NaOH}, \mathrm{NH}_{4} \mathrm{OH},\left(\mathrm{NH}_{4}\right)_{2} \mathrm{SO}_{4}$, and $\mathrm{NH}_{4} \mathrm{NO}_{3}$ were purchased from Merck company in analytical grade. Stock solutions of nitrate were prepared by adding the specific values of potassium nitrate $\left(\mathrm{KNO}_{3}\right)$ in deionized water. The $\mathrm{pH}$ was adjusted to the desired value with $1 \mathrm{M}$ $\mathrm{HCl}$ and $1 \mathrm{M} \mathrm{NaOH}$. The $\mathrm{NaCl}, \mathrm{KCl}$ and $\mathrm{Na}_{2} \mathrm{CO}_{3}$ solutions were prepared as the supporting electrolytes.

\subsection{Reactor Set-Up}

In this study, electrocoagulation process was combined with the air stripping system (Figure 1). The process consists of the electrochemical reactor $(1 \mathrm{~L})$, DC power supply (TEK-8051, $30 \mathrm{~V}$ and $5 \mathrm{~A}$ ), peristaltic pump (Watson Marlow $101 \mathrm{U} / \mathrm{R})$, and graphite and aluminum electrodes. The air stripping periods are considered 5, and 15 minutes between the two cycles. These periods were selected, to eliminate ammonia and other intermediates produced around the cathode during the process.

The process used four electrodes with the arrangement of graphite/Al/graphite/Al. The dimensions of the graphite and aluminum electrodes were $150 \times 60 \times 5 \mathrm{~mm}$ and $150 \times 60 \times 2 \mathrm{~mm}$, respectively. The distance between anode and cathode electrodes was fixed to $1 \mathrm{~cm}$. Before the starting-up of the process, the anode electrodes were cleaned with $1 \mathrm{M} \mathrm{H}_{2} \mathrm{SO}_{4}$ and rinsed with deionized water to eliminate impurities from the surface of the electrodes.

\subsection{Analysis}

All experiments were performed according to standard methods for the examination of water and wastewater. The samples were collected from the reactor and filtered to remove solid material. The nitrate and ammonium contents were measured byUV-spectrophotometer withan absorption maximum at $\lambda=220$ and $\lambda=640 \mathrm{~nm}$,respectively (Rayleigh UV 9200, China) (18). The pH and ORP were measured with a pH meter (Eutech) and an ORP probe.

\subsection{Response Surface Methodology}

Response Surface Methodology (RSM) includes the mathematical and statistical methods for modeling and determining the model equations. Also, this method is commonly used for improving and optimizing processes (19). We find a suitable function between the responses and a set of independent variables. This approximate function must be a polynomial of independent variables. Central composite design (CCD) was used to fit this model as the most famous design. In CCD, low axial, high axial, factorial and a central point are coded as $-2,+2,-1,+1$, and 0 , respectively.

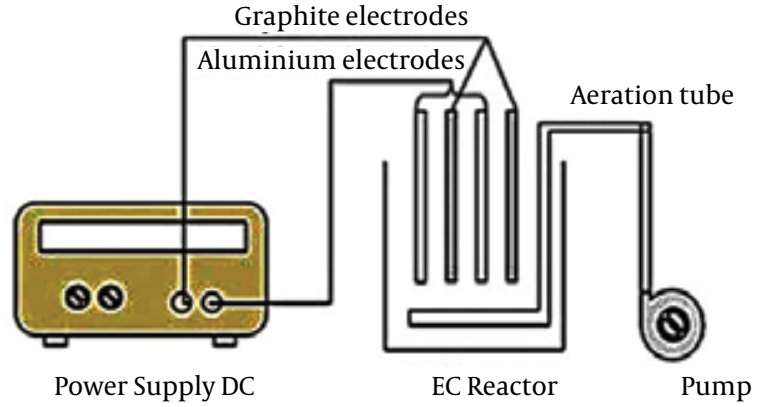

Figure 1. Schematic Diagram of Electrochemical Reactor

\subsection{Evaluation of Variables}

For modeling and optimization, two important factors were considered: initial concentration of nitrite, and applied electric current. Based on CCD, low axial, high axial, factorial and a central point were chosen as follows:

Initialconcentrations of nitritewere $\geq 50, \geq 72, \geq 125, \geq$ 178 , and $\geq 200 \mathrm{mg} / \mathrm{L}$;

Appliedelectriccurrentswere $\geq 0.05, \geq 0.072, \geq 0.125$, $\geq$ 0.178 , and $\geq 0.2 \mathrm{~A}$;

To determine the optimum conditions, supporting electrolyte $(\mathrm{NaCl}=1 \mathrm{~g} / \mathrm{L})$, anode/cathode: $\mathrm{Al} /$ graphite and detention period of 120 minutes were considered.

In the next step, based on optimum factors in RSM, effect of different supporting electrolytes $(\mathrm{NaCl}, \mathrm{KCl}$ and $\mathrm{Na}_{2} \mathrm{CO}_{3}$ ), nitrate intermediates, and oxidation reduction potential were optimized.

\section{Results}

Table 1 shows CCD and responses of each experiment. In this study, the electric current and nitrate concentration were optimized by RSM and designed thirteen runs for developing the model and coded removal equation. Figure 2 displays the contour and 3D response surface plots for the variables. The removal trend indicated the effects of two significant variables on cathodic reduction of nitrate. The statistical values as the R-squared, adjusted Rsquared and C.V\% that derived from experimental data are shown in Table 2. The R-squared, adjusted R-squared, the mean and C.V\% were 0.998132, 0.996798, 72.92\% and 1.449454 , respectively. As seen in Table 3, the prediction value is observed for models with $95 \%$ confidence interval (CI) and prediction interval (PI). Figure 3 displays the effect of different supporting electrolytes such as $\mathrm{NaCl}$, $\mathrm{KCl}$, and $\mathrm{Na}_{2} \mathrm{CO}_{3}$ on nitrate removal efficiency. Ammonia is the main intermediate of the nitrate in an electrochemical process, and its variations are illustrated in Figure 4. Finally, the variation of the oxidation reduction potential (during the electrocoagulation process at the optimum state) was investigated which its results can be seen in Figure 5. 
Hossini H et al.

Figure 2. Three Dimensions Diagram of the Variables for Nitrate Removal Efficiency

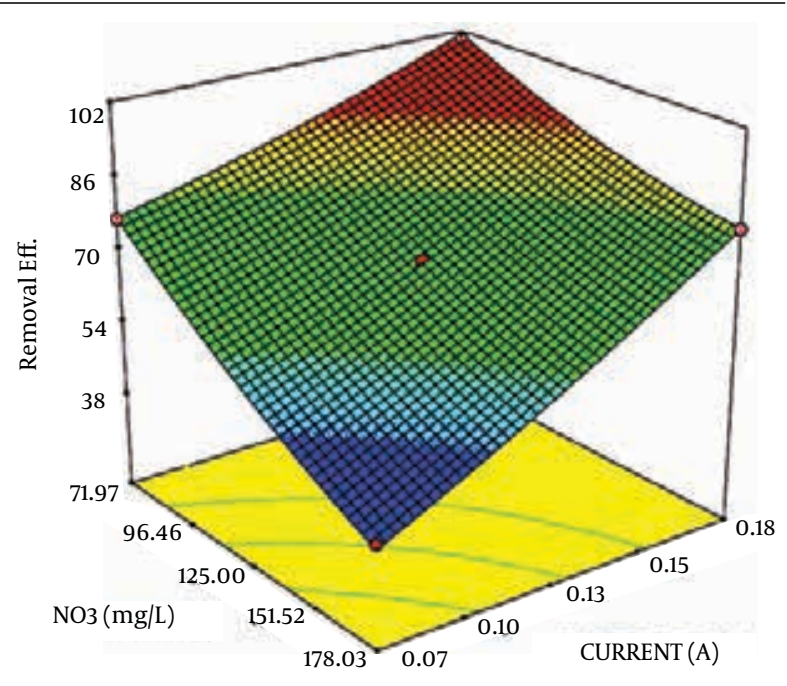

Conditions: $\mathrm{NaCl}=1 \mathrm{~g} / \mathrm{L}$, nitrate concentration range $=50-200 \mathrm{mg} / \mathrm{L}$, applied current range $=0.05-0.2 \mathrm{~A}$, anode $=\mathrm{Al}$ and cathode $=$ graphite, detention time $=120$ minutes.

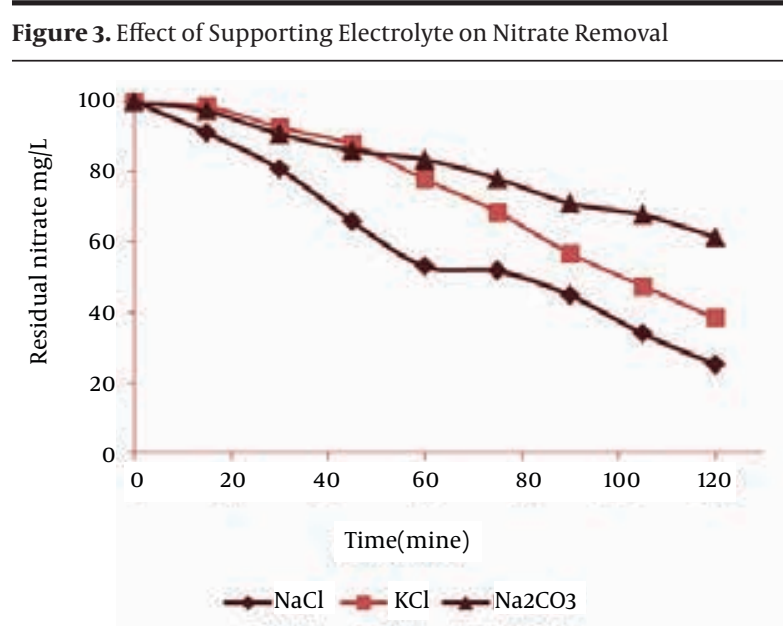

$\mathrm{NaCl}, \mathrm{KCl}$, and $\mathrm{Na}_{2} \mathrm{CO}_{3}=1 \mathrm{~g} / \mathrm{L}$, nitrate concentration $=100 \mathrm{mg} / \mathrm{L}$, applied current $=0.10 \mathrm{~A}$, anode $=$ aluminum and cathode $=$ graphite .

\section{Discussion}

\subsection{Statistical Analysis}

The percentage of reduced nitrate, $P$ Value and the variance analysis of the obtained data showed a significant value (Table 1). The P Value, lack of fit and $F$ value of the model were achieved $<0.0001,0.0729$, and $<748.1962$, respectively. Regarding the statistical values for nitrate reduced model, it displayed a high significant conformity (Table 2). Difference between $\mathrm{R}^{2}(0.998)$ and adjusted $\mathrm{R}^{2}(0.996)$ should be lower than 0.2 . In addition, the coefficient of the variation percentage $(\mathrm{CV} \% \sim 1.5)$ is the
Figure 4. Development of Ammonium During the Electroreduction of Nitrate at Optimum State

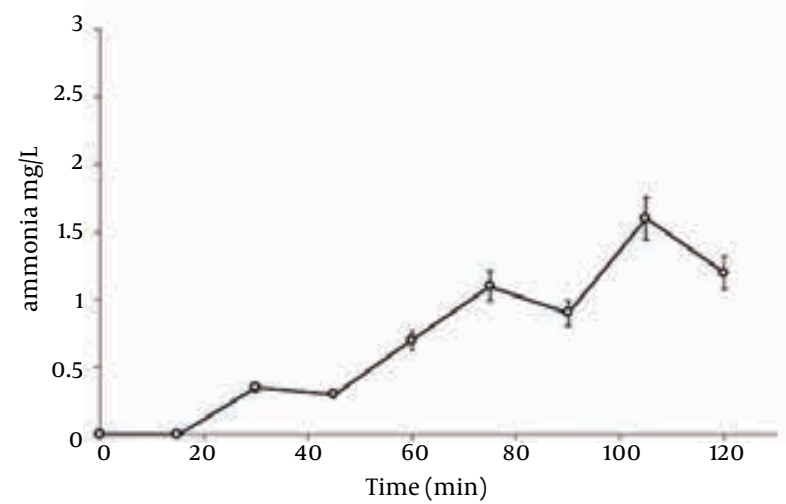

Condition: $\mathrm{NaCl}=1 \mathrm{~g} / \mathrm{L}$, nitrate concentration range $=176 \mathrm{mg} / \mathrm{L}$, applied current range $=0.14 \mathrm{~A}$, anode $=\mathrm{Al}$ and cathode $=$ graphite, detention time $=120$ minutes.

Figure 5. ORP Variations During the Electrocoagulation Process at Optimum State

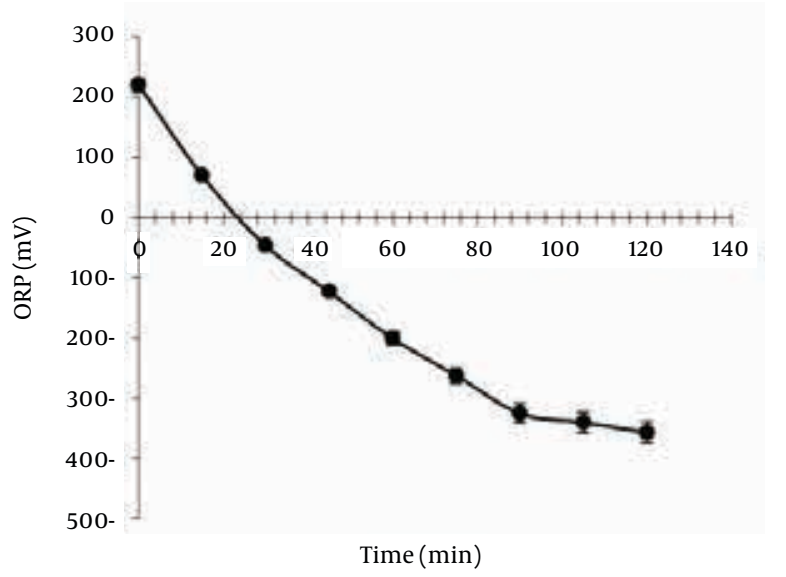

Condition: $\mathrm{NaCl}=1 \mathrm{~g} / \mathrm{L}$, nitrate concentration range $=176 \mathrm{mg} / \mathrm{L}$, applied current $=0.14 \mathrm{~A}$, anode $=\mathrm{Al}$ and cathode $=$ graphite, detention time $=120$ minutes.

value of the reproducibility of the model and should be lower than 10\% (20). Accordingly, the CV\% indicates the reliability and high precision of the experimental data. Adequate precision (about $\sim 88.26$ ) is the ratio of signal, and the figure should be greater than 4 in order to be desirable. The model removal was calculated from the coded factors equation (Equations 1).

Final equation in terms of coded Factors:

\section{Equation 1.}

Removal Percentage: $\mathrm{Eq}=+70.4-14.90 \mathrm{x}_{1}+16.79 \mathrm{x}_{2}+$ $4.75 \mathrm{x}_{1} \mathrm{x}_{2}+2.68 \mathrm{x}_{1}^{2}+1.43 \mathrm{x}_{2}{ }^{2}$

According to the Figure 2, the higher removal efficiency occurred in lower initial concentration and high applied 
Hossini $\mathrm{H}$ et al.

current. Also, lower removal rates can be seen in higher concentrations. Nitrate reduction rate shows a direct relation to the applied current and has reverse relationship by initial concentration. So, the $99 \%$ removal rate is observed in high current and low concentration. Bazrafshan et al. reported that the most effective removal capacities of nitrate
(96\%) could be achieved at 40 Volt, $\mathrm{pH} 10$, and reaction time 60 minutes for initial concentration of $5 \mathrm{mg} / \mathrm{L}$ nitrate (20). The results of Lacasa et al. indicated that electrocoagulation is an effective technology for nitrate removal because nitrate anions preferentially are adsorbed onto the surfaces of growing metal-hydroxide precipitates (21).

\begin{tabular}{lcccc}
\hline \multicolumn{5}{l}{ Table 1. The Central Composite Design and its Responses in Experimental and Coded Equation ConditionCondition } \\
\hline Run & $\mathbf{x}_{1}$ & $\mathbf{x}_{2}$ & Experimental Removal & Model Removal \\
\hline $\mathbf{1}$ & 0 & 0 & 71.2 & 70.4 \\
$\mathbf{2}$ & 0 & 1 & 98 & 88.62 \\
$\mathbf{3}$ & 0 & 1 & 100 & 88.62 \\
$\mathbf{4}$ & 0 & 0 & 69.6 & 70.4 \\
$\mathbf{5}$ & 0 & -1 & 49 & 55.04 \\
$\mathbf{6}$ & 2 & 1 & 81 & 79.04 \\
\hline $\mathbf{7}$ & 0 & -1 & 54 & 55.04 \\
$\mathbf{8}$ & 0 & 0 & 70 & 70.4 \\
$\mathbf{9}$ & 0 & 0 & 70.8 & 70.4 \\
$\mathbf{1 0}$ & -1 & -1 & 70.4 & 77.37 \\
$\mathbf{1 1}$ & -1 & -1 & 77 & 77.37 \\
$\mathbf{1 2}$ & 1 & 0 & 58 & 58.18 \\
\hline $\mathbf{1 3}$ & 0 & -2 & 39 & 42.54 \\
\hline
\end{tabular}

\begin{tabular}{|c|c|c|c|c|}
\hline Source & Sum of Squares & Mean Square & F Value & P Value Prob $>F$ \\
\hline Model & 4179.503 & 835.9005 & 748.1962 & $<0.0001$ \\
\hline $\mathrm{x}_{1}-\mathrm{NO}_{3}$ & 1776.837 & 1776.837 & 1590.408 & $<0.0001$ \\
\hline$x_{2}$-Current & 2254.443 & 2254.443 & 2017.902 & $<0.0001$ \\
\hline $\mathbf{x}_{1} \mathbf{x}_{2}$ & 90.25 & 90.25 & 80.78079 & $<0.0001$ \\
\hline$x_{1}^{2}$ & 49.77826 & 49.77826 & 44.55543 & 0.0003 \\
\hline $\mathbf{x}_{2}{ }^{2}$ & 14.12609 & 14.12609 & 12.64395 & 0.0093 \\
\hline Residual & 7.820547 & 1.117221 & - & - \\
\hline Lack of Fit & 6.220547 & 2.073516 & 5.183789 & 0.0729 \\
\hline Pure Error & 1.6 & 0.4 & - & - \\
\hline Cor Total & 4187.323 & - & - & - \\
\hline Result, Mean \pm SD & $72.92308 \pm 1.056987$ & - & - & - \\
\hline C.V., \% & 1.449454 & - & - & - \\
\hline Press & 46.735 & - & - & - \\
\hline $\mathbf{R}^{2}$ & 0.998132 & - & - & - \\
\hline Adjusted $\mathbf{R}^{2}$ & 0.996798 & - & - & - \\
\hline Pred $\mathbf{R}^{2}$ & 0.988839 & - & - & - \\
\hline Adequate precision & 88.26366 & - & - & - \\
\hline
\end{tabular}

\begin{tabular}{lcccc}
\hline Table 3. Prediction and Experimental Values with & 95\% Confidence Interval (CI) and Prediction Interval (PI) & \\
\hline Prediction & 95\% CI Low & 95\% CI High & 95\% PI Low & 95\% PI High \\
\hline 82.8064 & 81.52 & 84.09 & 80 & 85.62 \\
\hline
\end{tabular}


Hossini Het al.

\subsection{Optimum Condition}

The optimum condition for nitrate removal using electroreduction-flotation process was achieved using 176 $\mathrm{mg} / \mathrm{L}$ nitrate and 0.14 A electric current. The nitrate removal efficiency was gained $82.8 \%$ in the optimum conditions with regard to $95 \%$ confidence interval and prediction interval (Table 3). The experimental results obtained from optimum conditions revealed the precision of the resulting data and models.

\subsection{Effect of Supporting Electrolyte}

The use of supporting electrolyte can decrease interior resistance of electrolyte, lower energy consumption, and increase applied frequency in an electrochemical experiment. Although the nitrate ions can serve as a supporting electrolyte in the transfer of electrons during the electrochemical process, but addition of certain salts such as $\mathrm{NaCl}, \mathrm{KCl}$ and $\mathrm{Na}_{2} \mathrm{CO}_{3}$ can reduce the internal resistance of the electrolyte (22). According to Figure 3, nitrate reduction due to $\mathrm{NaCl}$, is better than $\mathrm{KCl}$ and $\mathrm{Na} 2 \mathrm{CO}$. Higher elimination of nitrate in the presence of $\mathrm{NaCl}$ may be due to higher ionization of this compound. The nitrate reduction of $\mathrm{NaCl}$ and $\mathrm{KCl}$ can occurre because of chlorine reaction on the anode electrode as follows (Equations 2 and 3 ):

Equation 2.

$2 \mathrm{cl}^{-} \rightarrow 2 \mathrm{cl}_{2}+2 \mathrm{e}^{-}$

Equation 3.

$\mathrm{Cl}_{2}+\mathrm{H}_{2} \mathrm{O} \rightarrow \mathrm{Hclo}+\mathrm{Hcl}$

\subsection{Removal of Ammonia as an Intermediate}

The main intermediates of nitrate in an electrochemical process are nitrite, $\mathrm{NH} 2 \mathrm{OH}$, and ammonia (Equations 4-9).

Equation 4.

$\mathrm{NO}_{3}^{-}+\mathrm{H} \_2 \mathrm{O}+2 \mathrm{e}^{-} \leftrightarrow \mathrm{NO}_{2}^{-}+2 \mathrm{OH}^{-} ; \mathrm{E}^{\circ}=10 \mathrm{mV}$

Equation 5.

$\mathrm{NO}_{3}{ }^{-}+3 \mathrm{H}_{2} \mathrm{O}+5 \mathrm{e}^{-} \leftrightarrow 0.5 \mathrm{~N}_{2}+6 \mathrm{H}^{-} ; \mathrm{E}^{\circ}=260 \mathrm{mV}$

Equation 6.

$\mathrm{NO}_{3}^{-}+6 \mathrm{H}_{2} \mathrm{O}+8 \mathrm{e}^{-} \leftrightarrow \mathrm{NH}_{3}+6 \mathrm{H}^{-} ; \mathrm{E}^{\circ}=-120 \mathrm{mV}$

Equation 7.

$\mathrm{NO}_{2}^{-}+2 \mathrm{H}_{2} \mathrm{O}+3 \mathrm{e}^{-} \leftrightarrow 0.5 \mathrm{~N}_{2}+4 \mathrm{OH}^{-} ; \mathrm{E}^{\circ}=-406 \mathrm{mV}$

Equation 8.

$\mathrm{NO}_{2}^{-}+5 \mathrm{H}_{2} \mathrm{O}+6 \mathrm{e}^{-} \leftrightarrow \mathrm{NH}_{3}+7 \mathrm{OH}^{-} ; \mathrm{E}^{\circ}=-165 \mathrm{mV}$

Equation 9.

$\mathrm{NO}_{2}^{-}+4 \mathrm{H}_{2} \mathrm{O}+4 \mathrm{e}^{-} \leftrightarrow \mathrm{NH}_{2} \mathrm{OH}+5 \mathrm{OH} ; \mathrm{E}^{\circ}=-450 \mathrm{mV}$

The nitrogen gas is the final environmental friendly product $(23,24)$. Generally, ammonia is produced during the electrochemical removal process of nitrate. It can be removed by air stripping. Figure 4 shows the various ammonia compounds during the process. The variation of the produced ammonia is due to the intermittent aeration that occurred after air is turned off. The dissolution of anode (aluminum) and produced monomeric, polymeric and amorphous species, such as $\mathrm{Al}(\mathrm{OH})_{3}, \mathrm{Al}(\mathrm{OH})^{2+}$, $\mathrm{Al}(\mathrm{OH})_{2}{ }^{2+}, \mathrm{Al}_{2}(\mathrm{OH})_{2}{ }^{4+}, \mathrm{Al}(\mathrm{OH})^{4-}, \mathrm{A}^{16}(\mathrm{OH})_{15}{ }^{3+}, \mathrm{Al}_{7}(\mathrm{OH})_{17}{ }^{4+}$, $\mathrm{Al}_{8}(\mathrm{OH})_{20}{ }^{4+}, \mathrm{Al}_{13} \mathrm{O}_{4}(\mathrm{OH})_{24}{ }^{7+}$, and $\mathrm{Al}_{13}(\mathrm{OH})_{34}{ }^{5+}$ is the main reason for the $\mathrm{pH}$ increase of the process $(25,26)$. Because of the dissolution of anode, $\mathrm{Al} 3+$ ions are released. The amount of aluminum released into the solution from the anode can be calculated by Faraday's law (Equation 10).

\section{Equation 10.}

$\mathrm{W}_{\mathrm{A}}=\mathrm{I} . \mathrm{t} . \mathrm{m} / \mathrm{n} . \mathrm{F}$

Where WA is the amount of dissolved anode $(\mathrm{g})$; I is the current intensity (A); $t$ is the run time (s); $m$ is the specific molecular weight (g/mol); F is Faraday's constant (96485 A-s $/ \mathrm{mol})$; and $\mathrm{n}$ is the number of electrons involved. The overall weight loss of anode ratio during the electrochemical process to theoretical state obtained about 1.3: 1. Near the surface of cathode, the water is hydrolyzed to $\mathrm{H} 2$ and $\mathrm{OH}$ (Equations 11 and 12). The aluminumhydroxide (Equation 13) is the final product of the reaction (27).

Equation 11.

Anodic Reactions: $\mathrm{AL} \rightarrow \mathrm{AL}^{+3}+3 \mathrm{e}^{-}$

Equation 12.

Cathodic Reactions: $2 \mathrm{H}_{2} \mathrm{O}+2 \mathrm{e}^{-} \rightarrow \mathrm{H}_{2}+2 \mathrm{OH}^{-}$

\section{Equation 13.}

$\mathrm{AL}^{+3}+3 \mathrm{OH}^{-} \rightarrow \mathrm{Al}(\mathrm{OH})_{3}$

Increasing the $\mathrm{pH}$ by the production of hydroxylated species can facilitate the release of ammonia to the atmosphere. Szpyrkowicz et al. (24) reported that the electroreduction of nitrate can be influenced by $\mathrm{pH}$ and cathodic potential. The cathodic potential depends more on anode/cathode material, than the electrolyte conditions and electric potential.

\subsection{Effect of Oxidation Reduction Potential}

The Oxidation Reduction Potential (ORP) is a main factor in the electrochemistry process. It is very important in the formation of intermediates of nitrogen such as $\mathrm{NO}_{3}, \mathrm{NO}_{2}$, and $\mathrm{NH}_{3}$. The nitrate reduction needs a reduction condition with a negative ORP. In the experiments, the ORPs were changed from +220 to $-375 \mathrm{mV}$ (Figure 5). With regard to the ORP, the produced nitrogen species mainly consists of the ammonia and nitrogen gases. Based on the relationship between the ORP and the concentrations of reduced and oxidized species involved in denitrification processes can be ensured that the denitrification is performed. The ORP has been widely used as a control parameter for online monitoring and control of nitrification and denitrification since 1980s (28). The operating ORP for nitrification and denitrification have been reported between -100 and $+100 \mathrm{mV}(28)$. Also, Ra et al. believed that the complete depletion of nitrate is occurred around -300 to $-400 \mathrm{mV}(29)$.

The results of this study shows that it is possible to remove the nitrate and its intermediates from wastewater, using an electrocoagulation process. According to the 
obtained results, it can be found that the aluminum/ graphite electrodes show nitrate removal with high performance. In this process, many operational factors such as $\mathrm{pH}$, supporting electrolyte, applied current, and initial nitrate concentration were found. RSM was used as an effective method and optimized the applied current and initial concentration of nitrate values at $176 \mathrm{mg} / \mathrm{L}$ and $0.14 \mathrm{~A}$, respectively. Furthermore, the RSM has been applied to develop the polynomial regression equations and evaluation the relation between the nitrate reduction and the experimental factors. Finally, with regard to the results, 90\% removal efficiency was obtained based on the optimized state, and this amount can be used reliably for field scales. Moreover, this process is able to reduce the nitrate according to WHO guidelines or USEPA MCL. Due to the desirable efficiency of electrocoagulation process the field scale assessment is recommended.

\section{Acknowledgements}

The authors acknowledge the financial support of Tarbiat Modares University.

\section{Authors' Contributions}

Mr. Abbas Rezaee was the main research designer and corresponding author. Mr. Hooshyar Hossini and Mr. Abbas Rezaee were both equally participated in this research.

\section{References}

1. Koizumi M, Tanaka M, Nishiki Y, Sekimoto M, Furuta T, Inoue H, et al. Reduction of nitrate ion using hydrogen permeating Pd foil electrodes. Res Chem Inter. 2006;32(5):585-94.

2. Rezaee A, Godini H, Jorfi S. Nitrate removal from aqueous solution using mgcl (2) impregnated activated carbon. Environ Eng Manag J.2010;9(3):449-52.

3. Camargo JA, Alonso A. Ecological and toxicological effects of inorganic nitrogen pollution in aquatic ecosystems: A global assessment. Environ Int. 2006;32(6):831-49.

4. Sparis D, Mystrioti C, Xenidis A, Papassiopi N. Reduction of nitrate by copper-coated ZVI nanoparticles. Desalination Water Treat. 2013;51(13-15):2926-33.

5. Schoeman JJ, Steyn A. Nitrate removal with reverse osmosis in a rural area in South Africa. Desalination. 2003;155(1):15-26.

6. Rezaee A, Godini H, Dehestani S, Yazdanbakhsh AR, Mosavi GR, Kazemnejad A. Biological denitrification by Pseudomonas stutzeri immobilized on microbial cellulose. World J Microbio Biotechnol. 2008;24(11):2397-2.

7. Dash BP, Chaudhari S. Electrochemical denitrificaton of simulated ground water. Water Res. 2005;39(17):4065-72.

8. Luk GK, Au-Yeung WC. Experimental investigation on the chemical reduction of nitrate from groundwater. Adv Environ Res . 2002;6(4):441-53.

9. Li M, Feng C, Zhang Z, Yang S, Sugiura N. Treatment of nitrate contaminated water using an electrochemical method. Bioresour Technol. 2010;101(16):6553-7.
10. Bi J, Peng $\mathrm{C}, \mathrm{Xu} H$, Ahmed AS. Removal of nitrate from groundwater using the technology of electrodialysis and electrodeionization. Desalin Water Treat . 2011;34(1-3):394-401.

11. Li M, Feng C, Zhang Z, Chen R, Xue Q, Gao C, et al. Optimization of process parameters for electrochemical nitrate removal using Box-Behnken design. Electrochimica Acta. 2010;56(1):265-70.

12. Aoudj S, Khelifa A, Drouiche N, Hecini M, Hamitouche H. Electrocoagulation process applied to wastewater containing dyes from textile industry. Chem Eng Process. 2010;49(11):1176-82.

13. Yahiaoui O, Lounici H, Abdi N, Drouiche N, Ghaffour N, Pauss A, et al. Treatment of olive mill wastewater by the combination of ultrafiltration and bipolar electrochemical reactor processes. Chem Eng Process. 2011;50(1):37-41.

14. Rezaee A, Hossini H, Masoumbeigi H, Cheshmeh Soltani R. Simultaneous Removal of Hexavalent Chromium and Nitrate from Wastewater using Electrocoagulation Method. Int J Environ Sc Develop. 2011;2(4):294-8.

15. Adhoum N, Monser L. Decolourization and removal of phenolic compounds from olive mill wastewater by electrocoagulation. Chem Eng Process. 2004;43(10):1281-7.

16. Benhadji A, Taleb Ahmed M, Maachi R. Electrocoagulation and effect of cathode materials on the removal of pollutants from tannery wastewater of Rouïba. Desalination. 2011;277(1-3):128-34.

17. Emamjomeh MM, Sivakumar M. Review of pollutants removed by electrocoagulation and electrocoagulation/flotation processes. J Environ Manage. 2009;90(5):1663-79.

18. American Public Health Association.. AWW, WPCF. Washington DC,USA: American Public Health Association; 2005.

19. Kobya M, Demirbas E, Bayramoglu M, Sensoy MT. Optimization of Electrocoagulation Process for the Treatment of Metal Cutting Wastewaters with Response Surface Methodology. Water Air Soil Pollut. 2010;215(1-4):399-410.

20. Bazrafshan E, Soori M, Mostafapour F, Jafarian H, Paseban A. Application of electrochemical process for nitrate removal from aqueous environments. JNKU. 2011;3(4):25-33.

21. Lacasa E, Cañizares P, Sáez C, Fernández FJ, Rodrigo MA. Removal of nitrates from groundwater by electrocoagulation. Chem Engin J. 2011;171(3):1012-7.

22. Soltani R, Rezaee A, Godini H, Khataee AR, Hasanbeiki A. Photoelectrochemical treatment of ammonium using seawater as a natural supporting electrolyte. Chem Ecol.2013;29(1):72-85.

23. Paidar M. Electrochemical removal of nitrate ions in waste solutions after regeneration of ion exchange columns. J Appl electrochem.1999;29(5):611-7.

24. Szpyrkowicz L, Daniele S, Radaelli M, Specchia S. Removal of $\mathrm{NO} 3$ - from water by electrochemical reduction in different reactor configurations. Appl Catal B-Environmt. 2006;66(1-2):40-50.

25. Kobya M, Can O, Bayramoglu M. Treatment of textile wastewaters by electrocoagulation using iron and aluminum electrodes. J Hazard Mater. 2003;100(1-3):163-78.

26. Katal R, Pahlavanzadeh H. Influence of different combinations of aluminum and iron electrode on electrocoagulation efficiency: Application to the treatment of paper mill wastewater. Desalination. 2011;265(1-3):199-205.

27. Mouedhen G, Feki M, Wery Mde P, Ayedi HF. Behavior of aluminum electrodes in electrocoagulation process. $J$ Hazard Mater 2008;150(1):124-35.

28. Lackner S, Lindenblatt C, Horn H. 'Swinging ORP' as operation strategy for stable reject water treatment by nitritation-anammox in sequencing batch reactors. Chem Engin J. 2012;180:190-6.

29. Ra CS, Lo KV, Mavinic DS. Real-Time Control of Two-Stage Sequencing Batch Reactor System for the Treatment of Animal Wastewater. Environ Technol.1998;19(4):343-56. 